\title{
Associations of Gain in Weight-Related Anthropometric Indices with a Marker of Lipid Peroxidation: A Cohort Study Among Urban Adults in China
}

This article was published in the following Dove Press journal:

Diabetes, Metabolic Syndrome and Obesity: Targets and Therapy

\author{
Tao $\mathrm{Xu}{ }^{1,2}$ \\ Bin Wang ${ }^{1,2}$ \\ Limin Cao ${ }^{1,2}$ \\ Weihong Qiu (1D) ${ }^{1,2}$ \\ Zhuang Zhang ${ }^{1,2}$ \\ Ailian Chen ${ }^{1,2}$ \\ Weihong Chen ${ }^{1,2}$ \\ 'Department of Occupational and \\ Environmental Health, School of Public \\ Health, Tongji Medical College, Huazhong \\ University of Science and Technology, \\ Wuhan, Hubei 430030, People's Republic \\ of China; ${ }^{2}$ Key Laboratory of \\ Environment and Health, Ministry of \\ Education and Ministry of Environmental \\ Protection, State Key Laboratory of \\ Environmental Health (Incubating), \\ School of Public Health, Tongji Medical \\ College, Huazhong University of Science \\ and Technology, Wuhan, Hubei 430030, \\ People's Republic of China
}

Correspondence: Weihong Chen Department of Occupational and Environmental Health, School of Public Health, Tongji Medical College, Huazhong University of Science and Technology, Wuhan, Hubei 430030, People's Republic of China

Tel +86278369l677

Email wchen@mails.tjmu.edu.cn
Background: Obesity is reported to be associated with oxidative stress which can cause lipid peroxidation. However, the effects of gain in various weight-related anthropometric indices on lipid peroxidation remain unclear. We aimed to examine the cross-sectional and longitudinal associations between altered weight-related anthropometric indices and a marker of lipid peroxidation among urban adults in China.

Methods: A total of 3762 participants from the Wuhan-Zhuhai cohort were included in the present study, with a follow-up of 3 years. Six weight-related anthropometric indicators were measured and calculated, including waist circumference (WC), body mass index (BMI), waist-to-hip ratio (WHR), waist-to-height ratio (WHtR), a body shape index (ABSI), and body adiposity index (BAI). Individual urinary 8 -iso-prostaglandin- $\mathrm{F}_{2 \alpha}\left(8\right.$-iso- $\left.\mathrm{PGF}_{2 \alpha}\right)$ was determined via enzyme-linked immunosorbent assay to evaluate lipid peroxidation. We used generalized linear models to analyze the cross-sectional and longitudinal associations of weight-related anthropometric indices with a marker of lipid peroxidation and stratified analyses to estimate effect modification.

Results: We found significant relationships between WHR, WHtR, ABSI, and urinary 8-iso$\mathrm{PGF}_{2 \alpha}$ at baseline. Each $1 \%$ increase in WHR, WHtR, and ABSI was significantly associated with a $0.007,0.004$, and 0.104 increase in log-transformed 8 -iso-PGF $2 \alpha$ concentration, respectively $(P<0.05)$. In longitudinal analysis, positive dose-response relationships were observed between gains in BMI, BAI, and increased 8-iso-PGF $2 \alpha$ after adjusting for potential confounders $\left(P_{\text {trend }}<0.05\right)$. We also found that gender and smoking status modified the association of BMI gain and 8-iso-PGF $2 \alpha$ increment, and such an association was more obvious in female and non-smokers.

Conclusion: Our research implied that gain in anthropometric indices may result in a higher level of lipid peroxidation.

Keywords: weight-related anthropometric indices, lipid peroxidation, obesity, cohort study

\section{Introduction}

Obesity, a widespread pandemic leading to poor health nowadays, has attracted worldwide public attention. According to the recent World Health Organization report, more than one third of the adult population were categorized as overweight or obese globally, as were over 340 million children and adolescents. ${ }^{1}$ Several weight-related indices have been used to assess adiposity, among which body mass index (BMI) is the most widely used. ${ }^{2}$ Compared with BMI, waist circumference 
(WC) and waist-to-hip ratio (WHR) have advantages in reflecting body fat distribution and measuring central obesity that is linked to greater health risks. ${ }^{3,4}$ Additionally, other weight-related anthropometric indices were proposed to assess the accumulation of adipose, including waist-toheight ratio (WHtR), a body shape index (ABSI), and body adiposity index (BAI). A review from Italian scholars reported that obesity may activate the innate immune system and promote oxidative stress. ${ }^{5}$

Oxidative stress arises from a systemic disequilibrium of oxidation-antioxidation system due to overproductions of reactive oxygen species (ROS) or reactive nitrogen species (RNS), which could contribute to the initiation and progression of obesity-related diseases. ${ }^{6-8}$ Cell membranes and macromolecules may be damaged once this imbalance appears. Lipids, especially polyunsaturated fatty acids, are susceptible biomolecules that could be attacked by ROS, and generate peroxides ultimately. F2isoprostanes $\left(\mathrm{F}_{2}\right.$-isoP) are regarded as reliable markers among numerous lipid peroxides. ${ }^{9}$ The 8 -iso-prostaglandin- $F_{2 \alpha}$ (8-iso- $\mathrm{PGF}_{2 \alpha}$ ), one well-known part of $\mathrm{F}_{2}$-isoP class, is usually detected in urine to reflect the level of lipid peroxidation. ${ }^{10}$ Some published literatures have suggested that elevated 8-iso-PGF $2 \alpha$ was associated with obesity and fat accumulation. ${ }^{11,12}$

To better achieve the early prevention of obesityrelated diseases, further understanding on the relationship between adiposity and lipid peroxidation is necessary. Ohmori et $\mathrm{al}^{13}$ found that the levels of plasma 8-iso$\mathrm{PGF}_{2 \alpha}$ were significantly higher in the high BMI group. In the Framingham Heart Study, positive associations of BMI and WHR with urinary 8-iso- PGF $_{2 \alpha}$ were also documented. ${ }^{14}$ However, a cross-sectional study of 677 Japanese people showed that BMI has no significant relevance to urinary 8 -iso- $\mathrm{PGF}_{2 \alpha}{ }^{15}$, which was inconsistent with the abovementioned findings. In addition to such controversial associations, independent effects of some new weight-related anthropometric parameters, such as ABSI and BAI, on urinary 8 -iso- $\mathrm{PGF}_{2 \alpha}$ remain largely unknown. And the study regarding the longitudinal associations of gain in weight-related anthropometric indices with urinary 8 -iso- $\mathrm{PGF}_{2 \alpha}$ change is limited. Accordingly, we aimed to investigate the effects of different weightrelated anthropometric indices on urinary 8 -iso- $\mathrm{PGF}_{2 \alpha}$ levels, and further examine whether there are longitudinal associations between gain in weight-related anthropometric indices and altered urinary 8-iso- $\mathrm{PGF}_{2 \alpha}$ levels among urban adults in China.

\section{Methods}

\section{Study Design and Population}

Data used in this study were originated from the WuhanZhuhai cohort, which is a community-based prospective cohort established between 2011 and 2012 as described previously. ${ }^{16}$ A total of 4812 participants aged $18-80$ years who lived in the communities of Wuhan or Zhuhai city for more than 5 years were recruited at baseline survey. Participants were followed up every 3 years. In the current cross-sectional analysis, 3762 subjects were included after excluding those with a history of nephritis $(\mathrm{n}=43)$, missing information on 8 -iso- $\mathrm{PGF}_{2 \alpha}(\mathrm{n}=926)$, and weight-related anthropometric indices $(\mathrm{n}=81)$ at baseline. The first follow-up survey was finished after 3 years, and a total of 2777 participants were recruited. We excluded participants who had missing data on weight-related anthropometric indices $(\mathrm{n}=1069)$ or failed to provide sufficient urine samples $(n=322)$. Finally, 1386 participants were included in longitudinal analysis. Participants included and excluded showed no significant difference in basic characteristics including age and gender. The study has approval from the Ethics and Human Subject Committee of Tongji Medical College, Huazhong University of Science and Technology. Written informed consent was gained from residents before participation.

\section{Covariate Data Collection}

Covariates, including basic demographic information, lifestyle (smoking status, alcohol drinking, regular physical activity, cooking status), and history of disease, were collected through face-to-face interview by professionals. Smoking status covered ever smoking (current and former smoking) and never smoking. Drinking status covered ever drinking (current and former drinking) and never drinking. Physical activity was defined as exercising regularly at least two times per week and for more than 20 minutes each time within the past 6 months. Diet information (intake frequencies of grains, fruit, vegetables, meat, and smoked each day or week) were also collected.

\section{Weight-Related Anthropometric Indices}

Every participant underwent a physical examination that included anthropometric measurements, like weight, height, WC, and hip circumference (HC). All of them were accomplished through standardized protocol and technique. In brief, height and weight were measured via weighing scale and a ruler (RGZ-120 Jiangsu Suhong 
Medical Device Co., Ltd, Changzhou, China). During the measurement, participants stood upright and kept the heels, sacrum, and scapula in line. WC was done at the midpoint between the iliac crest and the lower costal margin, and $\mathrm{HC}$ at the maximum circumference of the buttocks. Other weight-related anthropometric indices, including BMI, WHR, WHtR, ABSI, and BAI, were calculated as follows. ${ }^{17-19}$

$$
\begin{aligned}
& \mathrm{BMI}=\mathrm{Weight}(\mathrm{kg}) / \operatorname{Height}^{2}(\mathrm{~m}) \\
& \mathrm{WHR}=\mathrm{WC}(\mathrm{cm}) / \mathrm{HC}(\mathrm{cm}) \\
& \mathrm{WHtR}=\mathrm{WC}(\mathrm{cm}) / \operatorname{Height}(\mathrm{cm}) ; \\
& \mathrm{ABSI}=\mathrm{WC}(\mathrm{m}) /\left[\mathrm{BMI}^{2 / 3}\left(\mathrm{~kg} / \mathrm{m}^{2}\right) \operatorname{Height}^{1 / 2}(\mathrm{~m})\right] \\
& \mathrm{BAI}=\left[\mathrm{HC}(\mathrm{cm}) / \operatorname{Height}^{1.5}(\mathrm{~m})\right]-18 ;
\end{aligned}
$$

The gain in weight-related anthropometric indices were derived through the values of corresponding indicators in first follow-up minus the values at baseline. Overweight $\left(\geq 24 \mathrm{~kg} / \mathrm{m}^{2}\right)$ is defined based on the BMI cut-off values presented by the Working Group on Obesity in China. ${ }^{20}$

\section{Urinary 8-Iso-PGF2 $\alpha$ Determination}

We collected spot morning urine to detect the levels of urinary 8 -iso- $\mathrm{PGF}_{2 \alpha}$ that have been widely accepted in large epidemiological investigations previously. The levels of urinary 8-iso- $\mathrm{PGF}_{2 \alpha}$ were determined using a commercially available ELISA kit (Cayman Chemical, Ann Arbor, MI, USA) according to the manufacturer's instruction. We controlled the intra- and inter-assay coefficients of variation below $5 \%$ and $10 \%$, respectively. Urinary 8 -iso- $\mathrm{PGF}_{2 \alpha}$ concentration was calibrated by urinary creatinine $(\mathrm{Cr})$ and finally expressed as $\mathrm{ng} / \mathrm{mmol} \mathrm{Cr}$. Increased urinary 8-iso$\mathrm{PGF}_{2 \alpha}$ for each participant is the result of 8 -iso-PGF ${ }_{2 \alpha}$ in first follow-up minus the result at baseline.

\section{Statistical Analysis}

Urinary 8-iso- $\mathrm{PGF}_{2 \alpha}$ concentration was log-transformed because of its right skewed distribution. Demographic characteristics across urinary 8-iso- $\mathrm{PGF}_{2 \alpha}$ quartiles were compared using one-way ANOVA for continuous variables and Chi-square test for categorical variables.

The associations of weight-related and gain in weightrelated anthropometric indices with urinary 8-iso- $\mathrm{PGF}_{2 \alpha}$ and altered urinary 8-iso- $\mathrm{PGF}_{2 \alpha}$ levels were evaluated using generalized linear models with adjustment for potential confounders, including age, gender, city, education, smoking status, alcohol drinking, physical activity, cooking meals at home, intake frequency of each kind of food (fruit, meat, smoked), history of hypertension, diabetes, and coronary heart disease.

Continuous models were used to calculate the regression coefficient and 95\% confidence intervals of altered urinary 8 -iso- $\mathrm{PGF}_{2 \alpha}$ by each 1 -unit increase in weightrelated anthropometric indices, and categorical models to estimate regression coefficient of urinary 8 -iso- $\mathrm{PGF}_{2 \alpha}$ change across quartiles of different anthropometric indices gain. Furthermore, we assessed the relationships between altered urinary 8-iso- $\mathrm{PGF}_{2 \alpha}$ and transition of overweight status during a 3-year period in two models. One was adjusted for single study factor, and another for all potential confounders. Statistical modification was performed by inputting an interaction term of interested weight-related anthropometric indices multiplied by the stratification covariates (age, gender, smoking status, alcohol consumption, and physical activity) in the generalized linear models, so as to clarify the modification effect of baseline demographic characteristics. All analyses were performed using SAS 9.4 (SAS Institute Inc., Cary, NC, USA).

\section{Results}

\section{Baseline Characteristics of Participants}

The 8-iso- $\mathrm{PGF}_{2 \alpha}$ concentrations of all participants in urine samples ranged from 38.01-108.39 ng/mmol Cr, with a median value of $61.75 \mathrm{ng} / \mathrm{mmol} \mathrm{Cr}$. Baseline characteristics of the study population by quartiles of urinary 8-iso$\mathrm{PGF}_{2 \alpha}$ concentration are shown in Table 1. The mean age of 3762 subjects (1156 male, 30.73\%) was 52.07 \pm 13.56 years old. Male individuals, cigarette smokers, alcohol drinkers, and those who ate vegetables, fruits, and smoked food frequently were more likely to have a higher urinary 8 -iso- $\mathrm{PGF}_{2 \alpha}$ level, whereas the results were the opposite among individuals who exercise regularly, eat more meat, and usually cook meals at home $(P<0.05)$. As for weightrelated anthropometric parameters, no differences were found across urinary 8-iso- $\mathrm{PGF}_{2 \alpha}$ quartiles except for WHR and ABSI.

\section{Cross-Sectional Associations of Weight- Related Anthropometric Indices with Urinary 8-Iso-PGF2 $\alpha$}

The cross-sectional relationships between various weightrelated anthropometric indices and urinary 8 -iso-PGF $2 \alpha$ in all participants and subgroups of non-overweight and overweight are shown in Table 2. With adjustment for 
Table I Baseline Characteristics of Study Population by Quartiles of Urinary 8-Iso-PGF ${ }_{2 \alpha}$ Concentration (N=3762)

\begin{tabular}{|c|c|c|c|c|c|c|}
\hline \multirow[t]{2}{*}{ Characteristics } & \multirow{2}{*}{$\begin{array}{l}\text { All } \\
\text { Participants }\end{array}$} & \multicolumn{4}{|c|}{ Quartiles of Total Urinary 8-Iso-PGF ${ }_{2 \alpha}$ Levels, $\mathrm{ng} / \mathrm{mmol} \mathrm{Cr}$} & \multirow[t]{2}{*}{$P *$} \\
\hline & & $\begin{array}{l}\text { Quartile I } \\
(<38.01)\end{array}$ & $\begin{array}{l}\text { Quartile 2 } \\
(38.01-61.75)\end{array}$ & $\begin{array}{l}\text { Quartile } 3 \\
(61.75-108.39)\end{array}$ & $\begin{array}{l}\text { Quartile } 4 \\
(\geq 108.39)\end{array}$ & \\
\hline No, observations & 3762 & 940 & 941 & 940 & 941 & \\
\hline Age (years, mean $\pm S D$ ) & $52.07 \pm 13.56$ & $51.48 \pm 13.17$ & $51.84 \pm 13.28$ & $51.92 \pm 13.75$ & $53.05 \pm 14.00$ & 0.0706 \\
\hline Gender, n (\%) & & & & & & 0.0023 \\
\hline Female & $2606(69.27)$ & $696(74.04)$ & $649(68.97)$ & $632(67.23)$ & $629(66.84)$ & \\
\hline Male & $1156(30.73)$ & $244(25.96)$ & $292(31.03)$ & $308(32.77)$ & $312(33.16)$ & \\
\hline Education, n (\%) & & & & & & 0.0016 \\
\hline Middle school or below & $2280(60.61)$ & $590(62.77)$ & $593(63.02)$ & $567(60.32)$ & $530(56.32)$ & \\
\hline High school & $1020(27.11)$ & $222(23.62)$ & $232(24.65)$ & $274(29.15)$ & $292(31.03)$ & \\
\hline University or beyond & $462(12.28)$ & $128(13.62)$ & $116(12.33)$ & $99(10.53)$ & $119(12.65)$ & \\
\hline Smoking status, n (\%) & & & & & & $<0.0001$ \\
\hline Current or former smoker & 751 (19.96) & $135(14.36)$ & $178(18.92)$ & $209(22.23)$ & $229(24.34)$ & \\
\hline Never smoker & $3011(80.04)$ & $805(85.64)$ & $763(81.08)$ & 731 (77.77) & $712(75.66)$ & \\
\hline Drinking status, n (\%) & & & & & & $<0.0001$ \\
\hline Current or former drinker & $580(15.42)$ & $91(9.68)$ & $142(15.09)$ & $158(16.81)$ & $189(20.09)$ & \\
\hline Never drinker & $3182(84.58)$ & $849(90.32)$ & $799(84.91)$ & $782(83.19)$ & $752(79.91)$ & \\
\hline \multicolumn{7}{|l|}{ Dietary intake frequency } \\
\hline Meat (>4 times/week, n, \%) & $2487(66.11)$ & $651(69.26)$ & $643(68.33)$ & $614(65.32)$ & $579(61.53)$ & 0.0016 \\
\hline Fruit and vegetable (>4 times/week, n, \%) & $3547(94.28)$ & $874(92.98)$ & 875 (92.99) & $897(95.43)$ & 901 (95.75) & 0.0076 \\
\hline Smoked food (>I time/week, n, \%) & $849(22.57)$ & $178(18.94)$ & $209(22.21)$ & $214(22.77)$ & $248(26.35)$ & 0.0019 \\
\hline Physical activity, n (\%) & I843 (48.99) & $5 I I(54.36)$ & $483(51.33)$ & $433(46.06)$ & $416(44.2 I)$ & $<0.0001$ \\
\hline Cooking meals at home, $\mathrm{n}(\%)$ & 2781 (73.92) & $720(76.60)$ & $716(76.09)$ & $673(71.60)$ & $672(7 I .4 I)$ & 0.0094 \\
\hline \multicolumn{7}{|l|}{ Anthropometrics } \\
\hline BMI $\left(\mathrm{kg} / \mathrm{m}^{2}\right.$, mean $\left.\pm \mathrm{SD}\right)$ & $23.93 \pm 3.52$ & $23.83 \pm 3.60$ & $23.96 \pm 3.41$ & $23.86 \pm 3.53$ & $24.09 \pm 3.53$ & 0.3625 \\
\hline WC $(\mathrm{cm}$, mean $\pm S D)$ & $81.79 \pm 9.96$ & $81.10 \pm 9.99$ & $82.11 \pm 9.71$ & $81.74 \pm 9.97$ & $82.20 \pm 10.16$ & 0.0668 \\
\hline WHR $(\%$, mean $\pm S D)$ & $0.8678 \pm 0.0692$ & $0.8608 \pm 0.0707$ & $0.8719 \pm 0.0694$ & $0.8689 \pm 0.0692$ & $0.8696 \pm 0.067 \mid$ & 0.0030 \\
\hline WHtR $(\%$, mean $\pm S D)$ & $0.5158 \pm 0.0630$ & $0.5124 \pm 0.064 \mid$ & $0.5|8| \pm 0.061 \mid$ & $0.5148 \pm 0.0630$ & $0.5180 \pm 0.0635$ & $0.147 \mid$ \\
\hline ABSI $\left(\mathrm{m}^{7 / 6} / \mathrm{kg}^{2 / 3}\right.$, mean $\left.\pm \mathrm{SD}\right)$ & $0.0783 \pm 0.0049$ & $0.0780 \pm 0.0050$ & $0.0786 \pm 0.0047$ & $0.0784 \pm 0.0049$ & $0.0783 \pm 0.0050$ & 0.0487 \\
\hline BAI $\left(0.01 \mathrm{~m}^{-0.5}\right.$, mean $\left.\pm \mathrm{SD}\right)$ & $29.19 \pm 4.23$ & $29.29 \pm 4.28$ & $29.20 \pm 3.99$ & $29.00 \pm 4.23$ & $29.27 \pm 4.4 \mid$ & 0.4330 \\
\hline
\end{tabular}

Note: ${ }^{*} P$-values were estimated by one-way analysis of variance test for continuous variables and Chi-square test for categorical variables.

Abbreviations: WC, waist circumference; BMI, body mass index; WHR, waist-to-hip ratio; WHtR, waist-to-height-ratio; BAI, body adiposity index; ABSI, a body shape index; SD, standard deviation; $\mathrm{Cr}$, creatinine.

potential covariates, WHR, WHtR, and ABSI rather than BMI, WC, or BAI were significantly associated with 8-iso$\mathrm{PGF}_{2 \alpha}$ in all participants (Table 2 and Figure 1). Each $1 \%$ increase in WHR, WHtR, and ABSI was significantly associated with a $0.007,0.004$, and 0.104 increase in logtransformed 8-iso- $\mathrm{PGF}_{2 \alpha}$ concentration, respectively $(P<0.05)$. Additional subgroup analysis showed similar unanimous associations, and we found that the association of WHtR with 8-iso-PGF ${ }_{2 \alpha}$ is significant in the subgroup of non-overweight instead of overweight. The simple scatter plots with crude data between those relationships are shown in Supplementary Figure 1.

\section{Longitudinal Associations of Gain in} Weight-Related Anthropometric Indices with Altered Urinary 8-Iso-PGF $2 \alpha$

As shown in Figure 2, the results of generalized linear models indicated positive dose-response relationships between increased 8 -iso- $\mathrm{PGF}_{2 \alpha}$ and gain in BMI and BAI, after adjusting for potential confounders (all $\left.P_{\text {trend }}<0.05\right)$. Consistent with categorical analyses, continuous analyses exhibited that average increase in 8-iso$\mathrm{PGF}_{2 \alpha}$ was $2.65 \%(95 \% \mathrm{CI}=0.32-4.98 \%)$ with per 1 -unit gain in BAI $(P<0.05)$. Change in other weight-related anthropometric indices (BMI, WC, WHR, WHtR, and 
Table 2 Associations Between Weight-Related Anthropometric Indices and Urinary 8-Iso-PGF $2 \alpha$ Levels at Baseline (N=3762)

\begin{tabular}{|c|c|c|c|c|c|c|}
\hline \multirow[t]{2}{*}{ Variables } & \multicolumn{2}{|l|}{ All $(N=3762)$} & \multicolumn{2}{|l|}{ BMI<24 $(n=2003)$} & \multicolumn{2}{|l|}{ BMI $\geq 24(n=I 759)$} \\
\hline & $\beta(95 \% \mathrm{Cl})$ & $P$ & $\beta(95 \% \mathrm{Cl})$ & $\boldsymbol{P}$ & $\beta(95 \% \mathrm{Cl})$ & $P$ \\
\hline BMI & $-0.0010(-0.0084-0.0063)$ & 0.7796 & $0.0018(-0.0177-0.0213)$ & 0.8569 & $-0.0024(-0.0168-0.0121)$ & 0.7474 \\
\hline WC & $0.0018(-0.0009-0.0045)$ & 0.1987 & $0.0049(-0.0005-0.0103)$ & 0.0732 & $0.0028(-0.0023-0.0080)$ & 0.2817 \\
\hline WHR & $0.6805(0.2739-1.0872)$ & 0.0010 & $0.9256(0.3152-1.5360)$ & 0.0030 & $0.8427(0.1594-1.526 I)$ & 0.0157 \\
\hline WHtR & $0.4384(0.0052-0.8717)$ & 0.0473 & I.1828 (0.3157-2.0498) & 0.0075 & $0.6027(-0.2002-1.4056)$ & 0.1411 \\
\hline$A B S I$ & $10.3966(4.7817-16.0115)$ & 0.0003 & II.0364 (3.6652-18.4076) & 0.0034 & 10.1115 (1.3540-18.869I) & 0.0237 \\
\hline BAI & $0.0012(-0.0057-0.0082)$ & 0.7246 & $0.0076(-0.0062-0.0214)$ & 0.2797 & $-0.0013(-0.0123-0.0097)$ & 0.8179 \\
\hline
\end{tabular}

Notes: All models were adjusted for age, gender (male/female), city (Wuhan/Zhuhai), education (middle school or below/high/university or beyond), smoking status (current or former smoker/never smoker), alcohol status (current or former drinker/never drinker), exercise (time for physical activity), intake frequency of each food type (fruit ( $\leq 4 />4$ times/week), meat ( $\leq 4 />4$ times/week), smoked food ( $\leq 1 />1$ time/week)), cooking (yes/no), history of hypertension (yes/no), diabetes (yes/no), coronary heart disease (yes/no).

Abbreviations: WC, waist circumference; BMI, body mass index; WHR, waist-to-hip ratio; WHtR, waist-to-height-ratio; BAI, body adiposity index; ABSI, a body shape index.

ABSI) were positively associated with an increase in 8iso-PGF ${ }_{2 \alpha}$ without statistical significance (Supplementary Table 1). When contrasting with those overweight at baseline but non-overweight at follow-up, females who were non-overweight at baseline but overweight at follow-up showed a $42.15 \%(95 \% \mathrm{CI}=8.62-75.68 \%)$ increase in urinary 8 -iso- $\mathrm{PGF}_{2 \alpha}$ levels (Table 3 ).

Stratification analyses of selected characteristics are presented in Table 4. Gender and smoking status were potential effect modifiers of the association between BMI gain and altered urinary 8 -iso- $\mathrm{PGF}_{2 \alpha}$ levels $(P$ for interaction $<0.05)$, and no statistical significance was noted in other interaction terms. The relationships between BMI, as well as BAI gain and increased urinary 8 -iso- $\mathrm{PGF}_{2 \alpha}$, were more remarkable among females and nonsmokers. Thus, we then examined such associations in subgroups of different genders and smoking status. Among females or nonsmokers, but not males or smokers, significant dose-response relationships between anthropometric indices (BMI and BAI) gain and increased urinary 8-iso- $\mathrm{PGF}_{2 \alpha}$ still existed. In addition, individuals who cooked at home exhibited more pronounced associations compared with those did not cook (Supplementary Tables 2 and 3 ).

\section{Discussion}

In this study, we explored the cross-sectional and longitudinal associations of various weight-related anthropometric indices with urinary 8 -iso- $\mathrm{PGF}_{2 \alpha}$, a biomarker of lipid peroxidation. We observed that urinary 8 -iso- $\mathrm{PGF}_{2 \alpha}$ concentrations were increased along with elevated WHR, WHtR, and ABSI (an indicator reflecting body fat distributions) among all participants in the cross-sectional analysis. After follow-up of 3 years, we found significant dose-response relationships between gain in BMI and BAI and increased urinary 8 -iso- $\mathrm{PGF}_{2 \alpha}$ in longitudinal analysis. And such a relationship was more obvious in females and non-smokers than in males and smokers.

Data from a Framingham Heart Study involving 1250 adults showed that subcutaneous adipose tissue and visceral adipose tissue were related to higher urinary 8 -iso- $\mathrm{PGF}_{2 \alpha}$, which indicated a direct cross-sectional association of visceral adiposity and oxidative stress. ${ }^{21}$ In line with that, subsequent studies implied both general adiposity (accessed by BMI) and central adiposity (measured by WC and WHtR) were positively and similarly associated with lipid peroxidation. ${ }^{22-25}$ Besides, evidence from Japanese scholars found that the relationship between urinary F2-isoprostane (a lipid peroxidation marker) excretion and BMI showed a U-shaped curve with the lowest F2-isoprostane level at BMI 23 among 15 subjects. ${ }^{26}$ Indeed, our research also showed positive relationships between weight-related anthropometric indices (WHR, WHtR, ABSI) and urinary 8-iso-PGF ${ }_{2 \alpha}$ concentrations (a stable biomarker of lipid peroxidation), which indicated central obesity may contribute to lipid peroxidation by examining a large population in China. However, with respect to BMI, we did not find its effect on urinary 8-iso- $\mathrm{PGF}_{2 \alpha}$ at baseline, though this result was in accordance with a Japanese study conducted on 677 healthy adults. ${ }^{15}$ The possible explanations for the discrepancy between our findings and previously published data might be the differences in biological specimens and detection method of lipid peroxides. Blood specimens and mass spectrometric methods were applied in some prior research. While considering the short half-life of plasma $\mathrm{F}_{2}$-isoP and large sample size, ${ }^{15,27}$ immunoassays in urine may be a more suitable method. 

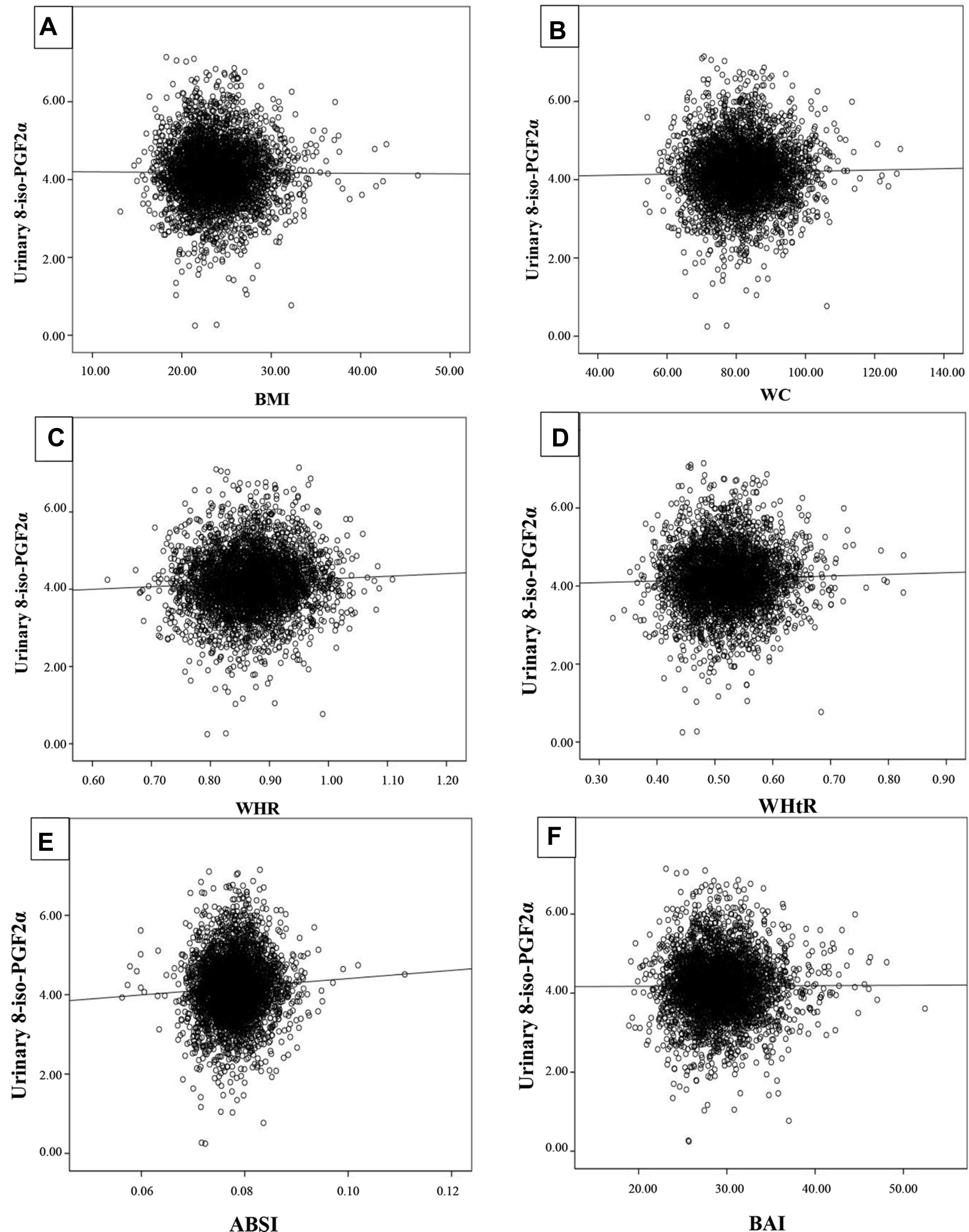

Figure I Associations between different weight-related anthropometric indices and urinary 8-iso-PGF ${ }_{2 \alpha}$ in baseline, adjusted for potential confounders ( $\left.\mathrm{N}=3762\right)$. Figures $\mathrm{A}$ to $\mathrm{F}$ represent the scatter plots of BMI $\left(\mathrm{kg} / \mathrm{m}^{2}\right)(\mathrm{A})$, WC (cm) (B), WHR (\%) (C), WHtR (\%) (D), ABSI $\left(\mathrm{m}^{7 / 6} / \mathrm{kg}^{2 / 3}\right)(\mathrm{E}), \mathrm{BAl}\left(0.01 \mathrm{~m}^{-0.5}\right)(\mathrm{F})$, and urinary 8-iso-PGF $2 \alpha$ concentrations, respectively. All models were adjusted for age, gender (male/female), city (Wuhan/Zhuhai), education (middle school or below/high/university or beyond), smoking status (current or former smoker/never smoker), alcohol status (current or former drinker/never drinker), exercise (time for physical activity), intake frequency of each food type (fruit ( $\leq 4 />4$ times/week), meat ( $\leq 4 />4$ times/week), smoked food ( $\leq 1 />1$ time/week), cooking (yes/no), history of hypertension (yes/no), diabetes (yes/no), coronary heart disease (yes/no).

Abbreviations: WC, waist circumference; BMI, body mass index; WHR, waist-to-hip ratio; WHtR, waist-to-height-ratio; BAI, body adiposity index; ABSI, a body shape index. 
$\triangle \mathrm{BMI}^{*}$

Quartile 4

Quartile 3

Quartile 2

Quartile 1

$\Delta \mathrm{WC}$

Quartile 4

Quartile 3

Quartile 2

Quartile 1

$\triangle$ WHR

Quartile 4

Quartile 3

Quartile 2

Quartile 1

$\triangle \mathrm{WHtR}$

Quartile 4

Quartile 3

Quartile 2

Quartile 1

$\triangle \mathrm{ABSI}$

Quartile 4

Quartile 3

Quartile 2

Quartile 1

$\triangle \mathrm{BAI}^{*}$

Quartile 4

Quartile 3

Quartile 2

Quartile 1 $\beta(95 \% \mathrm{CI})$

$0.1729(0.0248,0.3210)$

$0.0555(-0.0927,0.2038)$

$0.0732(-0.0749,0.2213)$

ref

$0.0879(-0.0626,0.2384)$

$-0.0143(-0.1626,0.1340)$

$-0.0459(-0.1948,0.1030)$

ref

$0.0267(-0.1267,0.1802)$

$-0.0128(-0.1650,0.1394)$

$-0.0832(-0.2322,0.0658)$

ref

$0.1185(-0.0302,0.2671)$

$0.0245(-0.1238,0.1728)$

$-0.0366(-0.1841,0.1110)$

ref

$-0.0527(-0.2016,0.0963)$

$0.0271(-0.1227,0.1770)$

$-0.1051(-0.2547,0.0444)$

ref

$0.1905(0.0378,0.3431)$

$0.2430(0.0945,0.3915)$

$0.1052(-0.0420,0.2523)$

ref

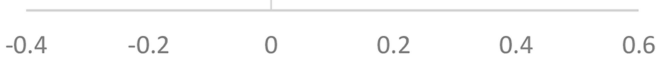

Figure 2 Associations between gain in weight-related anthropometric indices and change of urinary 8-iso-PGF $2 \alpha$ levels during 3-year follow-up ( $\mathrm{N}=1386$ ). All models were adjusted for age, gender (male/female), city (Wuhan/Zhuhai), education (middle school or below/high/university or beyond), smoking status (current or former smoker/never smoker), alcohol status (current or former drinker/never drinker), exercise (time for physical activity), intake frequency of each food type (fruit ( $\leq 4 />4$ times/week), meat ( $\leq 4 />4$ times/week), smoked ( $\leq 1 />1$ times/week), cooking (yes/no), history of hypertension (yes/no), diabetes (yes/no), coronary heart disease (yes/no). $* P_{\text {trend }}<0.05$. Abbreviations: WC, waist circumference; BMI, body mass index; WHR, waist-to-hip ratio; WHtR, waist-to-height-ratio; BAI, body adiposity index; ABSI, a body shape index.

To our knowledge, our present results provided vital insight into altered urinary 8 -iso- $\mathrm{PGF}_{2 \alpha}$ (a biomarker used to reflect the degree of lipid peroxidation) influenced by gain in weight-related anthropometric indices, which were largely unknown before. In the present study, as BMI or BAI levels keep increasing after 3 years, urinary 8-iso$\mathrm{PGF}_{2 \alpha}$ concentrations were gradually increased. Furthermore, compared with the female who lost weight during 3-year follow-up, those with gained weight had increased urinary 8 -iso- $\mathrm{PGF}_{2 \alpha}$, suggesting that the levels of lipid peroxidation may strengthen with growing fat accumulation over time, especially in women. A study by Chae et $\mathrm{al}^{28}$ found that 122 overweight/obese participants exhibited decreased urinary 8 -iso- $\mathrm{PGF}_{2 \alpha}$ after 3year-long intervention involving daily 100 -kcal calorie deficits. Il'yasova et $\mathrm{al}^{29}$ discovered that 2-year calorie restriction in healthy volunteers caused a statistical reduction in $\mathrm{F}_{2}$-isoP at both time points. Nevertheless, in the Insulin Resistance Atherosclerosis Study (IRAs) Cohort followed by 5 years, increased urinary $\mathrm{F}_{2}$-isoP levels predicted lower weight gain using the data from 299 individuals, ${ }^{30}$ which showed incongruity with our results. The heterogeneity may be owing to the discrepancy of subject characteristics and sample size. 
Table 3 Regression Coefficients of Change in Urinary 8-Iso-PGF2 $\alpha$ by Overweight at Baseline and 3-Year Follow-UP

\begin{tabular}{|c|c|c|c|c|}
\hline \multirow[t]{2}{*}{ Overweight at Baseline } & \multirow[t]{2}{*}{ Overweight at Follow-Up } & \multirow[t]{2}{*}{$\mathbf{N}$} & \multicolumn{2}{|l|}{$\beta(95 \% \mathrm{Cl})$} \\
\hline & & & Crude $^{\dagger}$ & Adjusted $^{\ddagger}$ \\
\hline \multicolumn{5}{|l|}{ All participants } \\
\hline Yes & No & 57 & ref & ref \\
\hline No & No & 530 & $0.2163(-0.0682-0.5008)$ & $0.1785(-0.0939-0.4508)$ \\
\hline Yes & Yes & 618 & $0.1531(-0.1294-0.4357)$ & $0.1380(-0.1323-0.4083)$ \\
\hline No & Yes & 181 & $0.2997(-0.0103-0.6097)$ & $0.2804(-0.0153-0.576 \mathrm{I})$ \\
\hline \multicolumn{5}{|l|}{ Females } \\
\hline Yes & No & 46 & ref & ref \\
\hline No & No & 384 & $0.2243(-0.0945-0.5431)$ & $0.2180(-0.0890-0.5249)$ \\
\hline Yes & Yes & 410 & $0.2183(-0.0994-0.5360)$ & $0.2183(-0.0856-0.5222)$ \\
\hline No & Yes & 131 & $0.4 \mid 32(0.063 \mid-0.7634)$ & $0.4215(0.0862-0.7568)$ \\
\hline
\end{tabular}

Notes: ${ }^{\dagger}$ Single factor for generalized linear regression. ${ }^{\ddagger}$ Adjusted for age, gender (male/female), city (Wuhan/Zhuhai), education (middle school or below/high/university or beyond), smoking status (current or former smoker/never smoker), alcohol status (current or former drinker/never drinker), exercise (time for physical activity), intake frequency of each food type (fruit ( $\leq 4 />4$ times/week), meat ( $\leq 4 />4$ times/week), smoked food ( $\leq 1 />1$ time/week)), cooking (yes/no), history of hypertension (yes/no), diabetes (yes/no), coronary heart disease (yes/no).

The explicit mechanism underlying the associations between weight-related anthropometric indices gain and higher level of lipid peroxidation over time remain not elucidated. The following pathways were likely to be involved. Enlarged white adipose tissue lead to the synthesis of various adipokines, which facilitate the generation of lipid peroxides in turn. ${ }^{31}$ Among adipokines, leptin serves as a crucial regulator for energy expenditure and food intake, and plays an important role in the formation of lipid peroxides; so as inflammatory cytokines from macrophages and monocytes, like TNF- $\alpha$, IL-1, and IL-6. ${ }^{23,32}$ Experimental models have observed that the nicotinamide adenine dinucleotide phosphate (NADPH) oxidase pathway (NOX) is another major source of ROS. ${ }^{33}$ NOX, particularly NOX4, shares the capacity to transfer electrons and convey various cellular signals. ${ }^{34}$ Marchesi et $\mathrm{al}^{35}$ found that vascular superoxide and NADPH oxidase activity was aroused in perivascular adipose tissue of New Zealand obese mice. In addition, susceptibility to lipid peroxidative injury is aggravating in obese individuals because of reduced antioxidant enzymes, such as superoxide dismutase (SOD), catalase (CAT), and glutathione peroxidase (GPX). ${ }^{31}$ Compared to those with a BMI of more than $40 \mathrm{~kg} / \mathrm{m}^{2}$, subjects with healthy BMI had significant higher SOD and GPX. ${ }^{36}$ And it has been proved that supplementation with antioxidants decreased systemic oxidative stress and plasma 8 -iso-PGF ${ }_{2 \alpha}$ concentrations among those of overweight or obese. ${ }^{37}$ Finally, visceral fat accumulation triggers increased lipid peroxidation through excess free fatty acids. ${ }^{5}$ As Randle et $\mathrm{al}^{38}$ identified that mitochondrial NADH/NAD+ ratio rose with high levels of fatty acid oxidation.
Interestingly, the females were more likely to have stronger associations between anthropometric indices (BMI and BAI) gain and 8-iso-PGF ${ }_{2 \alpha}$ increment, supporting the hypothesis that significant sex interactions were found between plasma 8-iso- $\mathrm{PGF}_{2 \alpha}$ levels and most measures of adiposity. ${ }^{23}$ The prior literatures have indicated that a higher adipose tissue volume in women than men may be responsible for the gender differences. ${ }^{23}$ Another possible interpretation was menopausal status. Most researches have shown increased lipid peroxidation levels and decreased antioxidant status were discovered in postmenopausal women, ${ }^{39,40}$ and women over 50 years old took up a large percentage in our study. The concrete reasons for the gender difference in the relationships need to be investigated in the future.

There are several strengths in our study. First and foremost, we clarified the relationships of weight-related anthropometric indices and urinary 8 -iso- $\mathrm{PGF}_{2 \alpha}$ via both cross-sectional and longitudinal analyses in a relatively large population. Besides, several weight-related anthropometric indices which could evaluate the fat accumulation from different dimensions were applied to offer a better understanding of the associations. Third, we adjusted for potential confounders such as cigarette smoking and drinking. As for our limitations, participants involved in this study were followed with a short interval, as such, the indices of anthropometry and lipid peroxidation may not reflect a long-term change. Further studies are needed to explore their associations for a long period in a larger population. Another limitation is that information about dietary intake habits, 
Table 4 Associations Between Gain in Weight-Related Anthropometric Indices and Change in Urinary 8-Iso-PGF2 $\alpha$ Levels During 3Year Follow-Up, Stratified by Selected Characteristics

\begin{tabular}{|c|c|c|c|c|c|c|c|}
\hline \multirow[t]{2}{*}{ Group } & \multirow[t]{2}{*}{$\mathbf{N}(\%)$} & \multicolumn{3}{|l|}{$\Delta \mathrm{BMI}$} & \multicolumn{3}{|l|}{$\Delta \mathbf{B A I}$} \\
\hline & & $\beta(95 \% \mathrm{Cl})$ & $P$ & $\begin{array}{l}P \text { for } \\
\text { Interaction }\end{array}$ & $\beta(95 \% \mathrm{Cl})$ & $P$ & $\begin{array}{l}P \text { for } \\
\text { Interaction }\end{array}$ \\
\hline \multicolumn{8}{|l|}{ Gender } \\
\hline Male & $415(29.94)$ & $-0.0377(-0.1102-0.0348)$ & 0.3078 & 0.0368 & $0.025 \mathrm{I}(-0.0234-0.0736)$ & 0.3096 & 0.9347 \\
\hline Female & 971 (70.06) & $0.0482(0.0105-0.0859)$ & 0.0123 & & $0.0285(0.0015-0.0555)$ & 0.0385 & \\
\hline \multicolumn{8}{|l|}{ Age, years } \\
\hline$<45$ & $290(20.92)$ & $0.0606(-0.0084-0.1295)$ & 0.0847 & 0.2574 & $0.0486(-0.0064-0.1037)$ & 0.0832 & 0.2596 \\
\hline $45-59$ & $656(47.33)$ & $0.0334(-0.0221-0.0890)$ & 0.2379 & & $0.0409(0.0057-0.0760)$ & 0.0229 & \\
\hline$\geq 59$ & $440(31.75)$ & $-0.0026(-0.0553-0.0502)$ & 0.9244 & & $0.0078(-0.0307-0.0464)$ & 0.6906 & \\
\hline \multicolumn{8}{|l|}{ Smoking status } \\
\hline Current or former & $266(19.19)$ & $-0.0540(-0.1449-0.0369)$ & 0.2429 & 0.0471 & $-0.014(-0.0804-0.0520)$ & 0.6723 & 0.2135 \\
\hline Never & II $20(80.81)$ & $0.0434(0.0077-0.0792)$ & 0.0174 & & $0.0336(0.0086-0.0587)$ & 0.0086 & \\
\hline \multicolumn{8}{|l|}{ Alcohol consumption } \\
\hline Current or former & $231(16.67)$ & $-0.0098(-0.1094-0.0898)$ & 0.8461 & 0.4640 & $0.0024(-0.0693-0.0742)$ & 0.9471 & 0.8011 \\
\hline Never & II55 (83.33) & $0.0331(-0.0022-0.0684)$ & 0.0664 & & $0.0286(0.0038-0.0534)$ & 0.0238 & \\
\hline \multicolumn{8}{|l|}{ Cooking } \\
\hline Yes & 1068 (77.06) & $0.0458(0.0087-0.0829)$ & 0.0155 & 0.0591 & $0.0294(0.004 \mathrm{I}-0.0547)$ & 0.0226 & 0.9475 \\
\hline No & $318(22.94)$ & $-0.0220(-0.0968-0.0527)$ & 0.5622 & & $0.0282(-0.033 \mathrm{I}-0.0896)$ & 0.3659 & \\
\hline
\end{tabular}

Notes: All models were adjusted for age, gender (male/female), city (Wuhan/Zhuhai), education (middle school or below/high/university or beyond), smoking status (current or former smoker/never smoker), alcohol status (current or former drinker/never drinker), exercise (time for physical activity), intake frequency of each food type (fruit ( $\leq 4 />4$ times/week), meat ( $\leq 4 />4$ times/week), smoked food $(\leq 1 />1$ times/week)), cooking (yes/no), history of hypertension (yes/no), diabetes (yes/no), coronary heart disease (yes/no).

Abbreviations: BMI, body mass index; BAl, body adiposity index.

smoking, and drinking status were obtained through questionnaires, and possible bias in recall may exist. In addition, although all persons participating in physical examination were trained by professionals on the basis of the same standard, there is also the chance for bias in anthropometric measurement. Further studies are needed to confirm our results.

\section{Conclusions}

In summary, we found that WHR, WHtR, and ABSI are powerful predictors of lipid peroxidation that was reflected by urinary 8 -iso- $\mathrm{PGF}_{2 \alpha}$ levels and associated closely with obesity-related health risks. Among females, pronounced dose-dependent relationships were reported between gain in BMI, BAI, and increased urinary 8 -iso- $\mathrm{PGF}_{2 \alpha}$. The study highlights that BAI and BMI may also be suitable indicators of dynamic response to lipid peroxidation.

\section{Abbreviations}

WC, waist circumference; BMI, body mass index; WHR, waist-to-hip ratio; WHtR, waist-to-height ratio; ABSI, a body shape index; BAI, body adiposity index; HC, hip circumference; 8-iso- $\mathrm{PGF}_{2 \alpha}$, 8-iso-prostaglandin- $\mathrm{F}_{2 \alpha} ; \mathrm{Cr}$, creatinine; ROS, reactive oxygen species; RNS, reactive nitrogen species; $\mathrm{F}_{2}$-isoP, F2-isoprostanes; NADPH, nicotinamide adenine dinucleotide phosphate; NOX, nicotinamide adenine dinucleotide phosphate oxidase pathway; SOD, superoxide dismutase; CAT, catalase; GPX, glutathione peroxidase; $\mathrm{SD}$, standard deviation.

\section{Data Sharing Statement}

The datasets used and analyzed in this study are available from the corresponding author with reasonable request.

\section{Ethics Approval and Informed Consent}

The study was approval by the Ethics and Human Subject Committee of Tongji Medical College, Huazhong University of Science and Technology. Written informed consent was gained from residents before participation.

\section{Acknowledgments}

We sincerely appreciated all participants recruited in the study and the support from the study team. 


\section{Author Contributions}

All authors made a significant contribution to the work reported, whether that is in the conception, study design, execution, acquisition of data, analysis and interpretation, or in all these areas; took part in drafting, revising or critically reviewing the article; gave final approval of the version to be published; have agreed on the journal to which the article has been submitted; and agree to be accountable for all aspects of the work.

\section{Funding}

This study was supported by the National Natural Science Foundation of China $(91,543,207$ and 91,843,302) and National Key Research and Development Program of China (2016YFC1303903).

\section{Disclosure}

The authors report no conflicts of interest for this work.

\section{References}

1. WHO. Fact sheet: obesity and overweight. Available from: http:// www.who.int/news-room/fact-sheets/detail/obesity-and-overweight. Accessed February, 2018.

2. Reilly JJ, El-Hamdouchi A, Diouf A, Monyeki A, Somda SA. Determining the worldwide prevalence of obesity. Lancet. 2018;391 (10132):1773-1774. doi:10.1016/S0140-6736(18)30794-3

3. Pischon T, Boeing H, Hoffmann K, et al. General and abdominal adiposity and risk of death in Europe. $N$ Engl J Med. 2008;359 (20):2105-2120. doi:10.1056/NEJMoa0801891

4. Boggs DA, Rosenberg L, Cozier YC, et al. General and abdominal obesity and risk of death among black women. $N$ Engl $J$ Med. 2011;365(10):901-908. doi:10.1056/NEJMoa1104119

5. Marseglia L, Manti S, D'Angelo G, et al. Oxidative stress in obesity: a critical component in human diseases. Int J Mol Sci. 2014;16 (1):378-400. doi:10.3390/ijms16010378

6. Higashi Y, Maruhashi T, Noma K, Kihara Y. Oxidative stress and endothelial dysfunction: clinical evidence and therapeutic implications. Trends Cardiovasc Med. 2014;24(4):165-169. doi:10.1016/j. tcm.2013.12.001

7. Brunelli E, La Russa D, Pellegrino D. Impaired oxidative status is strongly associated with cardiovascular risk factors. Oxid Med Cell Longev. 2017;2017:6480145. doi:10.1155/2017/6480145

8. Bigagli E, Lodovici M. Circulating oxidative stress biomarkers in clinical studies on type 2 diabetes and its complications. Oxid Med Cell Longev. 2019;2019:5953685. doi:10.1155/2019/5953685

9. Morrow JD, Hill KE, Burk RF, Nammour TM, Badr KF, Roberts LJ 2nd. A series of prostaglandin F2-like compounds are produced in vivo in humans by a non-cyclooxygenase, free radical-catalyzed mechanism. Proc Natl Acad Sci U S A. 1990;87(23):9383-9387. doi:10.1073/pnas.87.23.9383

10. Schwedhelm E, Bartling A, Lenzen H, et al. Urinary 8-iso-prostaglandin F2alpha as a risk marker in patients with coronary heart disease: a matched case-control study. Circulation. 2004;109 (7):843-848. doi:10.1161/01.CIR.0000116761.93647.30

11. Urakawa H, Katsuki A, Sumida Y, et al. Oxidative stress is associated with adiposity and insulin resistance in men. $J$ Clin Endocrinol Metab. 2003;88(10):4673-4676. doi:10.1210/jc.2003-030202
12. Costabile G, Della Pepa G, Bozzetto L, et al. Urine 8-isoprostane in relation to adiposity and insulin resistance in individuals at high cardiometabolic risk. Metab Syndr Relat Disord. 2015;13(4):187191. doi:10.1089/met.2014.0119

13. Ohmori K, Ebihara S, Kuriyama S, et al. The relationship between body mass index and a plasma lipid peroxidation biomarker in an older, healthy Asian community. Ann Epidemiol. 2005;15(1):80-84. doi:10.1016/j.annepidem.2004.04.001

14. Keaney JF Jr, Larson MG, Vasan RS, et al. Obesity and systemic oxidative stress: clinical correlates of oxidative stress in the Framingham Study. Arterioscler Thromb Vasc Biol. 2003;23 (3):434-439. doi:10.1161/01.ATV.0000058402.34138.11

15. Sakano N, Wang DH, Takahashi N, et al. Oxidative stress biomarkers and lifestyles in Japanese healthy people. J Clin Biochem Nutr. 2009;44(2):185-195. doi:10.3164/jcbn.08-252

16. Song Y, Hou J, Huang X, et al. The Wuhan-Zhuhai (WHZH) cohort study of environmental air particulate matter and the pathogenesis of cardiopulmonary diseases: study design, methods and baseline characteristics of the cohort. BMC Public Health. 2014;14:994. doi:10.1186/1471-2458-14-994

17. Krakauer NY, Krakauer JC, Li S. A new body shape index predicts mortality hazard independently of body mass index. PLoS One. 2012;7(7):e39504. doi:10.1371/journal.pone.0039504

18. Wang H, Liu A, Zhao T, et al. Comparison of anthropometric indices for predicting the risk of metabolic syndrome and its components in Chinese adults: a prospective, longitudinal study. BMJ Open. 2017;7 (9):e016062. doi:10.1136/bmjopen-2017-016062

19. Tripolino C, Irace C, Carallo C, Scavelli FB, Gnasso A. Body fat and blood rheology: evaluation of the association between different adiposity indices and blood viscosity. Clin Hemorheol Microcirc. 2017;65 (3):241-248. doi:10.3233/CH-16172

20. Zhou BF. Predictive values of body mass index and waist circumference for risk factors of certain related diseases in Chinese adults-study on optimal cut-off points of body mass index and waist circumference in Chinese adults. Biomed Environ Sci. 2002;15(1):83-96.

21. Pou KM, Massaro JM, Udo H, et al. Visceral and subcutaneous adipose tissue volumes are cross-sectionally related to markers of inflammation and oxidative stress. Circulation. 2007;116(11):12341241. doi:10.1161/CIRCULATIONAHA.107.710509

22. Wu SH, Shu XO, Chow WH, et al. Adiposity and fat distribution in relation to inflammation and oxidative stress in a relatively lean population of Chinese women. Dis Markers. 2013;34(4):279-293. doi: $10.1155 / 2013 / 437076$

23. Kanaya AM, Wassel CL, Stoddard PJ, et al. F 2 -Isoprostanes and adiposity in older adults. Obesity. 2011;19(4):861-867. doi:10.1038/ oby. 2010.243

24. An H, Du X, Huang X, et al. Obesity, altered oxidative stress, and clinical correlates in chronic schizophrenia patients. Transl Psychiatry. 2018;8(1):258. doi:10.1038/s41398-018-0303-7

25. Mure K, Yoshimura N, Hashimoto M, et al. Urinary 8-iso-prostaglandin F2 $\alpha$ as a marker of metabolic risks in the general Japanese population: the ROAD study. Obesity. 2015;23(7):1517-1524. doi:10.1002/oby.21130

26. Narukawa T, Anzai Y, Murakami T, Isogai R, Nakagawa S, Yamada H. Effects of Body Mass Index (BMI), dietary intake and serum antioxidant vitamin concentration on urinary 8-hydroxydeoxyguanosine and F2-isoprostane excretions. Aging Mech Dis. 2011;8(1):1-6. doi: $10.3793 /$ jaam. 8.1

27. Roberts LJ, Morrow JD. Measurement of F(2)-isoprostanes as an index of oxidative stress in vivo. Free Radic Biol Med. 2000;28 (4):505-513. doi:10.1016/S0891-5849(99)00264-6

28. Chae JS, Paik JK, Kang R, et al. Mild weight loss reduces inflammatory cytokines, leukocyte count, and oxidative stress in overweight and moderately obese participants treated for 3 years with dietary modification. Nutr Res. 2013;33(3):195-203. doi:10.1016/j.nutres.20 13.01 .005 
29. Il'yasova D, Fontana L, Bhapkar M, et al. Effects of 2 years of caloric restriction on oxidative status assessed by urinary F2-isoprostanes: the CALERIE 2 randomized clinical trial. Aging Cell. 2018;17(2):e12719.

30. Il'yasova D, Wang F, Spasojevic I, Base K, D'Agostino RB Jr, Wagenknecht LE. Urinary F2-isoprostanes, obesity, and weight gain in the IRAS cohort. Obesity. 2012;20(9):1915-1921. doi:10.1038/ oby.2011.292

31. Fernandez-Sanchez A, Madrigal-Santillan E, Bautista M, et al. Inflammation, oxidative stress, and obesity. Int J Mol Sci. 2011;12 (5):3117-3132. doi:10.3390/ijms12053117

32. Bondia-Pons I, Ryan L, Martinez JA. Oxidative stress and inflammation interactions in human obesity. J Physiol Biochem. 2012;68 (4):701-711. doi:10.1007/s13105-012-0154-2

33. Lopez-Acosta O, de Los Angeles Fortis-barrera M, Barrios-Maya MA, Ramirez AR, Aguilar FJA, El-Hafidi M. Reactive oxygen species from NADPH oxidase and mitochondria participate in the proliferation of aortic smooth muscle cells from a model of metabolic syndrome. Oxid Med Cell Longev. 2018;2018:5835072. doi:10.1155/2018/5835072

34. Bedard K, Krause KH. The NOX family of ROS-generating NADPH oxidases: physiology and pathophysiology. Physiol Rev. 2007;87 (1):245-313. doi:10.1152/physrev.00044.2005

35. Marchesi C, Ebrahimian T, Angulo O, Paradis P, Schiffrin EL. Endothelial nitric oxide synthase uncoupling and perivascular adipose oxidative stress and inflammation contribute to vascular dysfunction in a rodent model of metabolic syndrome. Hypertension. 2009;54(6):1384 1392. doi:10.1161/HYPERTENSIONAHA.109.138305
36. Olusi SO. Obesity is an independent risk factor for plasma lipid peroxidation and depletion of erythrocyte cytoprotectic enzymes in humans. Int J Obes Relat Metab Disord. 2002;26(9):1159-1164. doi:10.1038/sj.ijo.0802066

37. Sutherland WH, Manning PJ, Walker RJ, de Jong SA, Ryalls AR, Berry EA. Vitamin E supplementation and plasma 8-isoprostane and adiponectin in overweight subjects. Obesity. 2007;15(2):386-391. doi:10.1038/oby.2007.546

38. Randle PJ, Garland PB, Hales CN, Newsholme EA. The glucose fatty-acid cycle. Its role in insulin sensitivity and the metabolic disturbances of diabetes mellitus. Lancet. 1963;1(7285):785-789. doi:10.1016/S0140-6736(63)91500-9

39. Pansini F, Cervellati C, Guariento A, et al. Oxidative stress, body fat composition, and endocrine status in pre- and postmenopausal women. Menopause. 2008;15(1):112-118. doi:10.1097/gme.0b013e318068b285

40. Sánchez-Rodríguez MA, Zacarías-Flores M, Arronte-Rosales A, Correa-Muñoz E, Mendoza-Núñez VM. Menopause as risk factor for oxidative stress. Menopause. 2012;19(3):361-367. doi:10.1097/ gme.0b013e318229977d

Diabetes, Metabolic Syndrome and Obesity: Targets and Therapy

Dovepress

\section{Publish your work in this journal}

Diabetes, Metabolic Syndrome and Obesity: Targets and Therapy is an international, peer-reviewed open-access journal committed to the rapid publication of the latest laboratory and clinical findings in the fields of diabetes, metabolic syndrome and obesity research. Original research, review, case reports, hypothesis formation, expert opinion and commentaries are all considered for publication. The manuscript management system is completely online and includes a very quick and fair peer-review system, which is all easy to use. Visit http://www.dovepress.com/testimonials.php to read real quotes from published authors.

Submit your manuscript here: https://www.dovepress.com/diabetes-metabolic-syndrome-and-obesity-targets-and-therapy-journal 